\title{
Prestressed concrete
}

\author{
by Y. Guyon
}

Published by Contractors Record and Municipal Engineering, London. 1953. Price 70s. pp. XVI, 543.

In the development of any new engineering technique it is inevitable that progress on practical development should outstrip progress on research, and the narrowness of the gap between the two is the measure of the success of the research worker. By his very nature he will not commit himself to any opinion until his work has been checked and double checked, while the world of commerce and industry urges him to produce more and more results in less and less time.

For this reason a book written by an engineer with an aptitude for true development work, and yet with the inquiring mind of the pure research worker, is one that commands interest; and when the subject is prestressed concrete and the author is Monsieur Guyon, with his long association with Freyssinet, the "father" of prestressing, the book becomes one that must be studied as a real authority.

In his book Monsieur Guyon makes no attempt to cover the whole field of prestressed concrete. His thesis is that the process of prestressing is a general principle rather than a particular method and that once the general principles are understood they may be applied with ease to any particular method in which his reader is interested. This volume, therefore, is concerned only with the study of statically determinate straight beams, but all the problems that arise are dealt with in such great detail that the theories propounded may be applied to a variety of other types of construction.

The author assumes no prior knowledge of the principles of prestressed concrete in his reader and sets out his basic ideas in the first chapter in a way that is easily understood. This is closely associated with the following two chapters in which the properties of the basic materials, concrete and steel, are discussed and a review of standard prestressing methods and equipment is given.

The other chapters in the first part of the book deal in turn with the various phenomena associated with the production of a prestressed concrete unit, such as the anchorage stresses at the ends of both pre- and posttensioned beams, the problems associated with anchorage by bond and the effect of friction between the cable and its duct during tensioning, and the resistance of prestressed concrete units to attack by fire. Each of these chapters gives a wealth of information to the prestressed concrete engineer, and especially interesting are the two on anchorage stresses and friction. Knowledge is sadly lacking on both these problems and the theories and examples given virtually break fresh ground.

The second part of the book is concerned with the elastic design of simply-supported beams, in which Monsieur Guyon quotes practical design formulae and illustrates them with a wide variety of worked examples.

As with the first section the study is conducted in such a way that the design methods adopted may be applied to a variety of other structures. The author makes it clear, however, that while the elastic theories permit of a method of design that will enable structural members to be erected so as to carry their working loads safely, they take no account of the large margin of safety that exists once the elastic range of stress and strain in the concrete has been exceeded and the effect of plasticity becomes important. Methods of evaluating this margin, however, must take account of the behaviour of concrete in its higher stress ranges and involve a study of the redistribution of internal stress that takes place once cracking has occurred in the structural member.

It is the study of this elasto-plastic condition in prestressed concrete beams loaded to failure with which the third section of the book deals. The results of a number of different beam tests are analysed and certain phenomena noted that appear to be common to all prestressed concrete structures. Monsieur Guyon shows how these results may be used to supplement present elastic design methods and, indeed, almost replace them, so that full advantage may be taken of elasto-plastic behaviour.

The book is a free translation from Monsieur Guyon's original and the translators have succeeded in their object of expressing the author's point of view and argument rather than his personality. The exposition is simple and clear, and it is to be hoped that a second volume, dealing with statically indeterminate structures, will soon be forthcoming.

To criticise Monsieur Guyon's book is difficult, because of the obvious care with which it has been written. One might perhaps say that it contains too much information, in that it is not always easy for a practising designer to pick out the main information of interest to him from each section, but this is a small point in a work that is likely to establish itself as a standard work of reference for many years. 